\title{
The use of the ketogenic diet in the treatment of epileptic encephalopathies
}

\section{Roberto H Caraballo MD}

Department of Neurology, Hospital de Pediatría "Prof Dr Juan P Garrahan", Buenos Aires, Argentina

Corresponding author: Roberto Caraballo, Department of Neurology, Hospital de Pediatría Juan P. Garrahan, Combate de los Pozos 1881. Buenos Aires, Argentina CP 1245, Telephone Number: +54 1148240299.

Fax Number: +54 114843 6116.e-mail: rhcaraballo@arnet.com.ar

\begin{abstract}
Epileptic encephalopathies (EE) are severe conditions characterized by multiform and intractable seizures, paroxysmal activity on the electroencephalogram (EEG) that is often aggressive, associated with severe cognitive and behavioural disturbances that present or worsen after the onset of epilepsy. The ketogenic diet (KD) has been shown to be effective in the treatment of refractory EE, and has been suggested for early treatment in very young children.

Although the experience is often anecdotal and mostly consists of case reports and case series, the aim of this study was to present our own experience with an overview of the current literature on the diet in patients with EE.

Some encephalopathies, such as epilepsy with myoclonic and atonic seizures (EMAS), West syndrome (WS), Dravet syndrome (DS), or Lennox-Gastaut syndrome (LGS), are well recognized and known to have a good response to the KD. Others are more rare or have only recently identified, so the KD has only been tried in sporadic cases (i.e. epilepsy with focal migrating seizures in infancy, febrile infection-related epilepsy syndrome, or myclonic status in non-progressive encephalopathy). The KD should be considered earlier in the therapeutic scheme of these severe epileptic syndromes. The KD, including the oral formula, may be considered in all paediatric patients with EE even in infancy.
\end{abstract}

Keywords: Epileptic encephalopathies, ketogenic diet, children, refractory, outcome.

(C) 2018 Caraballo; licensee JICNA

\section{INTRODUCTION}

Epileptic encephalopathies (EE) are severe conditions characterized by paroxysmal activity on the electroencephalogram (EEG) that is often aggressive, manifesting as seizures that are commonly multi-form and intractable, and associated with severe cognitive and behavioural disturbances. These syndromes differ regarding age at onset, developmental outcomes, aetiologies, neuropsychological deficits, EEG patterns, seizure types, and prognosis [1], but have in common that the cause of the progressive cognitive and neuropsychological deterioration is considered to be related to the seizures and severe epileptiform EEG abnormalities during brain maturation [2, 3].

Recently, Howell et al. [4] proposed to restrict the term EE to the central concept of a pervasive epileptic process disrupting development rather than to consider them as epileptic syndromes. Based on these definitions, in this review we considered the following list of EE according to age at onset (see also Table 1):

- Early myoclonic encephalopathy (EME)

- Early infantile epileptic encephalopathy, or Ohtahara syndrome (OS)

- Infantile spasms (IS), or West syndrome (WS)

- Epileptic spasms in clusters without hypsarrhythmia

- Severe myoclonic epilepsy in infancy (SMEI), or Dravet syndrome (DS)

- $\quad$ Migrating partial seizures in infancy (MFSI)
- $\quad$ Epilepsy with myoclonic and atonic seizures (EMAS), or Doose syndrome

- Myoclonic status epilepticus in nonprogressive encephalopathies (MSENPE), or Dalla Bernardina syndrome

- Lennox-Gastaut syndrome (LGS)

- Landau-Kleffner syndrome (LKS) or Acquired epileptic aphasia

- Epilepsy with continuous spike-waves during slowwave sleep (CSWS)

- Febrile infection-related epilepsy syndrome (FIRES)

The factors that play a role in the development towards EE are often not identified [2]. The aetiologies may be genetic, structural/metabolic, or unknown. Considering that the cognitive and behavioural disturbances are caused by the epileptic and epileptiform activity, suppressing this activity may lead to improvement of the neuropsychological outcome. Nevertheless, EE are usually refractory to standard antiepileptic drugs (AEDs), leading to a need for other treatment options, such as more aggressive use of AEDs, immunomodulatory therapy, the ketogenic diet (KD), vagus nerve stimulation (VNS), and/or surgery.

The KD is a high-fat low-carbohydrate adequate-protein diet that has been in use since 1921. Although its mechanism of action is not well defined, the KD has been shown to be effective in the treatment of refractory EE, and has been suggested as an early treatment option in very young children $[5,6,7]$. 
The effect of the KD on some encephalopathies, such as EMAS, IS or WS, DS, or LGS, is well established. However, its effect on others is only reported sporadically (i.e., epilepsy with focal migrating seizures in infancy, Febrile infection-related epilepsy syndrome, or myclonic status in non-progressive encephalopathy, about which little is known).

In the treatment of epilepsy, the classic diet with a 1:4 or $1: 3$ ratio of fat to carbohydrates and proteins is used. Special formulas have been developed that facilitate the use of the diet in children with feeding difficulties due to severe neurological damage. Other diets available today, such as the medium chain triglyceride (MCT) diet, the modified Atkins diet (MAD), and the low glycaemic index treatment (LGIT), have broadened the armamentarium for the treatment of children and adults with difficult-to-treat epilepsies.

Although the experience is sometimes anecdotal and consists mostly of case reports and series, the aim of this study was to present our own experience with the KD and an overview of the current literature on the diet in patients with EE.

\section{EARLY MYOCLONIC ENCEPHALOPATHY}

Early myoclonic encephalopathy (EME) is a syndrome with onset either in the neonatal period or the first months of life characterized by erratic, fragmentary, or massive myoclonus, partial seizures, and late tonic spasms. The EEG shows a typical burst-suppression pattern. Family and birth history are typically normal.

The infants show severe neurological impairment. Abnormal neurological behaviour may be present prior to onset of seizures. Head size is typically normal at onset, but microcephaly may develop over time. Severe developmental delay is seen with or without regression.

The etiology of EME may be metabolic or genetic/metabolic. In particular, nonketotic hyperglycinaemia has been diagnosed in a large number of cases [8]. The prognosis for EME is poor, and there is no effective therapy.

In the literature, very few cases of EME treated with the KD have been published. Cusmai et al. [9] reported three cases affected by neonatal nonketotic hyperglycinaemia and EME. In association with standard pharmacological therapy, the KD caused a dramatic reduction of seizures and improved quality of life. More recently, we studied two refractory cases with unknown etiology. The KD was introduced with $75-90 \%$ seizure-reduction, and a significant improvement of the EEG abnormalities. The burst-suppression pattern disappeared in both cases.

\section{EARLY INFANTILE EPILEPTIC ENCEPHALOPATHY, OR OHTAHARA SYNDROME}

Ohtahara syndrome (OS) is an epileptic encephalopathy with seizure onset occurring within the first three months of life, often in the first ten days, characterized by mainly brief tonic seizures or epileptic spasms, and a pattern of burst activity on the EEG [8].

It is a severe disorder associated with intractable seizures and severe mental disability. No single cause of OS has been identified. The etiology is mainly structural, but genetic causes may also be recognized. Different mutations have been held responsible for the syndrome [10].

Because many cases of OS evolve to other seizure disorders, namely WS and LGS [8], the treatment window is small and little is known about the effect of the KD in these children. Reports in the literature are therefore scarce. Sivaraju et al. [11] reported a 5-year-old child with OS who failed to respond to AEDs. One year after starting the diet, he had a substantial reduction in seizure frequency as well as clear behavioural improvement. The authors concluded that, although patients with OS invariably have medically intractable seizures and a catastrophic neurodevelopmental outcome, the KD should still be considered for this group of patients.

Ishii et al. [12] reported a one-month-old male infant with OS. They attempted different therapies without success: high-dose pyridoxal phosphate and AEDs (sodium valproate, phenobarbital, clonazepam, and clobazam) in various doses and combinations, as well as adrenocorticotropic hormone $(\mathrm{ACTH})$, thyrotropin releasing hormone, and gamma-globulin. After trying the KD his seizures were brought under control. Considering these results, we believe that the KD should be introduced earlier in this group of patients.

\section{INFANTILE SPASMS OR \\ WEST SYNDROME}

Infantile spasms (IS), also known as West syndrome (WS), are the most common type of epileptic encephalopathy. Age at onset is between 3 and 7 months, but cases with onset before 3 months or after 12 months to 5 years are also found. The syndrome is characterized by spasms, arrest of psychomotor development, and a pattern of hypsarrhythmia on the EEG recording. The spasms are characterized by symmetric contractions of the trunk, with extension and elevation of the arms, and tonic extension of the legs lasting for less than 1 second to up to 5 seconds, and with clusters of 3-20 spasms typically occurring several times per day. Mild or severe developmental delay pre-exists in around $60 \%$ of the cases.

The etiology of IS is mostly structural and unknown in about 20\%. Different mutations have been found in children with IS [10]. The prognosis for patients with IS is poor and related to the etiology.

Management options are vigabatrin or ACTH, which control the spasms in two-thirds of the patients. Final outcome may not be influenced by treatment. Resective neurosurgery can be indicated for selected cases with localized structural lesions.

The KD is relatively well studied in this group of patients. In 2001, Nordli et al. [13] published a retrospective review of 32 infants who had been treated with the KD. They found that infants with IS/myoclonic seizures did particularly well on the diet. The study is particularly relevant as it shows that it is possible to effectively use the diet in infants, against the previous beliefs that is was difficult to maintain the ketoses in this group of patients.

Ville et al. [14] reported a series of 42 consecutive patients with corticosteroid-resistant or -dependent epileptic encephalopathy treated with oral steroids combined with the KD. Four our of 23 patients with WS responded to the diet. The addition of the KD allowed withdrawing steroids in all responders.

Hirano et al. [15] reported six patients with IS who received the KD after other treatments had failed, including ACTH. Hypsarrhythmia disappeared 1 month after the introduction of KD in five of the patients. The frequency of IS fell by $80 \%$ in three patients, and disappeared in two of them; and no change was observed in one patient. Psychomotor 
development improved in five patients. Although tolerance to the diet was good, side effects, such as lethargy, anorexia, and unfavourable weight gain, were observed.

Lee et al. [16] studied 69 patients with IS. Fourteen were put on the KD after they failed two or more AEDs, and seven of these patients became spasm-free.

Pires et al. [17] evaluated the effect of the KD in 17 infants with IS as a third-line treatment, after vigabatrin and steroids had failed. Six were seizure free after 1 month, and 11 were seizure free after 3 months on the diet. An additional AED (felbamate or topiramate) was given to all patients who did not become seizure free on the KD. The KD was well tolerated and felbamate led to an increase in the responder rate.

Numis et al. [18] studied the relationship of ketosis and growth to the efficacy of the KD in IS on 26 patients. At 1-3 months after diet initiation, $46 \%$ of patients had a greater than $90 \%$ reduction in IS. They found that the KD did not significantly alter the growth parameters of the patients.

Kang et al. [19] compared short-term (16 patients over 8-month period) and conventional long-term (24 patients over more than 2 years) KD treatment in patients with refractory IS who successfully completed the diet. The authors concluded that early response to the KD may indicate a successful early discontinuation of the KD and that the use of the KD for only 8 months in spasm-free children appears to be justified, with similar outcomes, recurrence rate, and less growth disturbance than with the longer-term, traditional use.

In a large study of 104 infants placed on the KD for IS after receiving a mean of 3.6 AEDs, Hong et al. [20] found that at 6 months, $64 \%$ of patients had over $50 \%$ spasm improvement, and $77 \%$ of patients improved after $1-2$ years. $37 \%$ of patients became spasm-free for at least 6 months within a median 2.4 months of starting the KD. In addition to this, development improved in $62 \%$, the EEG improved in $35 \%$, and AEDs could be reduced in $29 \%$ of cases. Adverse effects were noted in $33 \%$, of which $6 \%$ had diminished linear growth. Older age at onset of IS and fewer prior AEDs were more likely to be associated with more than $90 \%$ spasm improvement at 6 months.

Kossoff et al. [21] compared the results of the KD against ACTH for new-onset IS in a retrospective study, hypothesizing that the KD would have similar efficacy, but better tolerability than ACTH when used first-line. They found that the KD stopped spasms in $62 \%$ of cases, against the $90 \%$ registered on ACTH; however, those patients on the KD had fewer side effects and relapses than patients receiving $A C T H$. ACTH normalized the EEG more rapidly. In the five children where the KD was unsuccessful, four immediately became spasm-free with ACTH or topiramate. The authors concluded that the KD should be a first-line therapy for IS, with a 2-week time limit if unsuccessful.

We are currently evaluating 10 patients with WS treated with the KD. Three of them have an unknown etiology; one has become seizure free and two have had a $75-99 \%$ seizure reduction. Three patients with a structural etiology had a 50$75 \%$ seizure reduction. The remaining four patients did not respond to the diet. We believe the KD should be considered earlier in the treatment of WS, but not as the first option.

\section{EPILEPTIC SPASMS IN CLUSTERS WITHOUT HYPSARRHYTHMIA}

Some infants may have epileptic spasms and psychomotor delay in the absence of documented hypsarrhythmia. These patients who lack hypsarrhythmia may be considered to have a variant of WS, rather than an electroclinically distinct epileptic syndrome. How to place this syndrome nosologically is beyond the scope of this review; however, it is worth noting that two of our patients have responded well to the diet.

The etiology of epileptic spasms in clusters without hypsarrhythmia is structural and a focal brain lesion should be considered (i.e., cortical dysplasia, tuberous sclerosis, or a tumor) [22]. Patients with a genetic or unknown etiology have also been described. The prognosis is poor as the epileptic spams often do not respond to medical or surgical treatment [23].

Children with epileptic spasms in clusters without hypsarrhythmia may be candidates for ACTH therapy as the seizure pattern is identical to IS.

In our series of 48 patients with epileptic spasms without hypsarrhythmia [24], three patients were put on the KD. Seizure reduction was between $50 \%$ and $75 \%$ in one, between $25 \%$ and $50 \%$ in another, and the remaining patient did not respond to the treatment.

\section{SEVERE MYOCLONIC EPILEPSY IN INFANCY OR DRAVET SYNDROME}

Severe myoclonic epilepsy in infancy (SMEI) or Dravet syndrome (DS) is a rare disorder occurring in previously healthy infants. Age at onset is in the first year of life, with a peak at 5 months. The main clinical features are prolonged and repeated febrile and afebrile generalized or unilateral convulsive seizures, myoclonic jerks, and atypical absences most commonly occurring on arousal and during alert states. Seizures are often triggered by hot temperatures or fever.

The etiology is mostly genetic, related to mutations in sodium channel genes. One third of the children with DS show de novo mutations of the SCN1A gene, and additional familial genes probably contribute to the phenotype.

Molecular genetic testing is important, as the clinical features develop over time. Early diagnosis is key to prevent uncontrolled seizures leading to cognitive impairment.

DS is drug resistant. Some AEDs, such as carbamazepine, lamotrigine, and phenytoin, have been shown to worsen the seizures, while stiripentol in combination with valproate and clobazam may reduce them.

From our original series published in 2005 [25] and updated in 2011 [26], of 59 patients seen between 1990 and 2007, 24 were placed on the KD and were followed up for a minimum of 2 years. Sixteen $(66.6 \%)$ of 24 patients remained on the diet. Two patients (12.5\%) became seizure free; 10 children $(62.5 \%)$ had a $75-99 \%$ decrease in seizures; and the remaining four $(25 \%)$ had a $50-74 \%$ decrease in seizures. Furthermore, six patients have been off the diet for more than 2 years; one of them is seizure free, two have sporadic seizures, and three, who abandoned the diet after 3 years of adhering to it, relapsed. Twelve of 16 children who remained on the diet had a significant reduction in the number of seizures. Over the last years 20 new patients have been put on the diet with similar results. We consider that the KD is the most important treatment not only for the seizures but also for the febrile status epilepticus in patients with DS. In patients with an excellent response to the diet, neuropsychological performance improves significantly and thus, early treatment may avoid cognitive impairment.

Nabbout et al. [27] prospectively enrolled 15 DS patients over 3 years of age with a partial response to AEDs, includ- 
ing stiripentol, for treatment with the KD. At 1 month, 10 of their patients $(66 \%)$ had a $75 \%$ decrease in seizure frequency. Efficacy was maintained in eight responders at 3 and 6 months, and in six responders at 9 months. Five patients (33\%) remained on the KD over 12 months, and one became seizure free. They found that the KD also improved behaviour disturbances including hyperactivity even in a few nonresponders.

Dressler et al. [28] retrospectively analysed 32 children with DS to evaluate efficacy and safety of the KD, and compared the effects on seizure count with that of different AED regimens and VNS. Response to the KD was $70 \%$ at 3 months, and $60 \%$ at 12 months. No status epilepticus occurred while patients were on the diet, and the frequencies of prolonged generalized and myoclonic seizures were reduced. No severe side effects requiring withdrawal of the KD were observed. They found that noncompliance was more frequent in solid-fed older children compared with infants treated with the liquid KD formula.

In a series undertaken by Laux et al. [29], 13 out of 20 children with DS treated with the KD experienced a greater than $50 \%$ reduction in seizure frequency.

\section{MIGRATING PARTIAL \\ SEIZURES IN INFANCY}

Migrating partial seizures in infancy (MFSI) is an epileptic encephalopathy with a seizure onset in the first 6 months of life characterized by almost continuous migrating polymorphous focal seizures, associated with multifocal ictal EEG discharges, progressive deterioration of psychomotor development combined with frequent evolution of acquired microcephaly, and a typical ictal electroencephalography pattern consisting of seizures that arise independently and sequentially from both hemispheres [30]. The etiology is probably genetic with a heterogeneous basis [10].

The prognosis is poor as the seizures are resistant to AEDs. However, some patients may respond favourably to bromide, stiripentol associated with clonazepam, and levetiracetam.

Results of KD treatment are variable in these patients [31]. At our centre, three patients who presented with MFSI refractory to AEDs before 5 months of age were put on the $\mathrm{KD}$ [32]. One of these patients became seizure-free and his neurocognitive performance improved significantly. The other child had a seizure reduction of $75 \%$ to $99 \%$ with only weekly seizures and moderate psychomotor improvement. The remaining patient had a seizure reduction of less than $50 \%$. Tolerability was good in all three patients.

Recently, we have been studying four new patients with MFSI with an excellent response to the diet. Seizures decreased $75-99 \%$ in all subjects. Based on these positive preliminary results, earlier initiation of the KD should be considered in the treatment of patients with MFSI.

\section{EPILEPSY WITH MYOCLONIC AND ATONIC SEIZURES OR DOOSE SYNDROME}

Epilepsy with myoclonic and atonic seizures (EMAS) or Doose syndrome is a generalized epilepsy syndrome associated with multiple seizure types, including myoclonic-astatic, absence, tonic-clonic and eventually tonic seizures, appearing in a previously healthy child between 18 and 60 months of age, with a peak around the age of 3 years. The course of the disorder has variable severity [33]. Background EEG activity can be normal at seizure onset, although characteristic 4-7 $\mathrm{Hz}$ monomorphic theta activity with diffuse distribution but prominent in centro-parietal areas is often observed. Interictal abnormalities consist of bursts of $2-3 \mathrm{~Hz}$ generalized polyspike-and-wave discharges. Sleep is accompanied by an increase in generalized discharges [33].

Our series of 11 patients with EMAS placed on the KD [34] showed the diet is a promising therapy with over half of children showing a $>50 \%$ reduction in seizures, and $18 \%$ achieving seizure freedom. The patients that responded well to the diet did not further mentally deteriorate. The youngest child on the KD in our series of patients with EMAS was 4 years old. That is partly due to the fact that patients with EMAS often respond well to AEDs and the KD is only tried later in the treatment. We conclude that the KD should be considered early in the course of the syndrome, and not as a last resort.

Studies by Oguni et al., Sills et al., and Laux et al. also suggest that the KD is the most effective therapy for patients with EMAS [33, 35, 36].

\section{MYOCLONIC STATUS EPILEPTICUS IN NONPROGRESSIVE ENCEPHALOPATHIES OR DALLA BERNARDINA SYNDROME}

Myoclonic status epilepticus in nonprogressive encephalopathies (MSENPE) is characterized by the recurrence of long-lasting status associated with absences and continuous polymorphous myoclonias, mixed with other complex abnormal movements in infants suffering from a nonprogressive encephalopathy, independently of the etiology. Age at first seizure ranges from 1 month to 4 years, with a mean age of 16 months and a median age of 10 months.

This condition may be difficult to recognize clinically because of previous intellectual deficits and continuous abnormal movements. However, it can be identified on polygraphic recordings. [37]

The prognosis of MSENPE is poor. The children show progressive deterioration resulting in severe neurocognitive impairment. The myoclonic status resolves with age, but the patients rarely achieve a relatively normal state.

The etiology can be diverse, but is mainly genetic and due to a malformation of cortical development. Angelman syndrome is the most frequent underlying cause of MSENPE.

Awareness of this syndrome is important because, although it occurs in children with severe neurological damage, its diagnosis and treatment may improve the quality of life of the patients and their families. There is no effective treatment other than benzodiazepines, which transiently interrupt the myoclonic status epilepticus.

Our experience with three patients with MSENPE placed on the KD was variable. One had a $75 \%-99 \%$ seizure-reduction; another one had a $50 \%$ seizure-reduction; and the remaining case did not respond to the diet [37]. Three other patients had a good response to KD with a more than $50 \%$ of seizure-reduction (Dalla Bernardina, personal communication). In five of these six cases the etiology was genetic.

\section{LENNOX-GASTAUT SYNDROME}

Lennox-Gastaut syndrome (LGS) is a disorder characterized by clusters of seizures and mental retardation, with an age at onset from 1 to 7 years. Tonic seizures, atonic seizures, and atypical absences are the characteristic seizures, in this or- 
der of prevalence. Falls are common. Nonconvulsive status epilepticus of atypical absences, tonic and atonic seizures, and myoclonic jerks occur in half of the patients. Motor, cognitive, and behavioural abnormalities are found in around $60 \%$ of the patients prior to seizure onset. After that, nearly all have severe neurological and mental deficits.

Etiology is structural; in $70 \%$ of cases, there were severe brain disorders and malformations of cortical development. The remaining cases are unknown or genetic/metabolic cases.

The prognosis of LGS is poor; $5 \%$ of the patients die and $80 \%$ to $90 \%$ continue having seizures in adult life with severe neurological and mental deficits.

Complete seizure control is unlikely. Different AEDs and steroids are occasionally helpful. The KD has been successfully tried in different studies, although further studies are required to determine optimal timing to start the diet and which type of diet would be the best [38]. VNS is an option in patients with LGS [39]. Corpus callosotomy can be considered for intractable drop attacks.

In our series of 61 patients with LGS [40], 20 were placed on the diet. After 18 months, 15 patients $(75 \%)$ remained on the diet; three patients (15\%) were seizure free, three (15\%) had a $75-99 \%$ decrease in seizures, two (10\%) had a $50-$ $74 \%$ decrease in seizures, and the remaining seven children $(35 \%)$ had less than $50 \%$ decrease in seizures. Three seizure-free patients were taken off the diet after remaining seizure free. In the three patients who had a $75-99 \%$ decrease in seizures, AEDs were reduced. We found that the KD is an effective and well-tolerated treatment option for patients with LGS, not only for those with an unknown etiology, but also for those with structural LGS. The diet should be considered early in the course of this syndrome.

Lemmon et al. [41] retrospectively studied the records of 71 children, with LGS who were initiated on the KD between 1994 and 2010. They found that approximately one-half of children responded at 12 months.

Sharma et al. [42] used the MAD to treat 25 children with LGS. After 3 months, two patients were seizure-free and 10 had over $50 \%$ reduction in seizure frequency. At 6 months, three patients were seizure free, and eight had more than $50 \%$ reduction in seizure frequency. At 1 year, all nine children remaining on diet had more than $50 \%$ reduction in seizure frequency. The side effects of the diet were mild. The MAD was found to be effective and well tolerated in children with LGS.

\section{LANDAU-KLEFFNER SYNDROME (LKS) OR ACQUIRED EPILEPTIC APHASIA}

Landau-Kleffner syndrome (LKS), or acquired epileptic aphasia, is a rare disorder characterized by linguistic abnormalities (in $100 \%$ of cases) and seizures (in $75 \%$ of cases) in previously normal children. The age of onset ranges from 2-8 years, with a peak between 5 and 7 years. Onset as early as 18-22 months and as late as 13-14 years has also been reported. The most prominent feature of LKS is an acquired aphasia, typically, a verbal auditory agnosia. The loss of receptive language is followed by expressive aphasia, with a marked reduction in spontaneous speech. The aphasia demonstrates a subacute onset and a progressive course, with a fluctuating pattern of spontaneous improvements and exacerbations. Electroencephalographic findings during wakefulness may be bilateral centrotemporal, posterior temporal, and parieto-occipital spikes and waves. As soon as the patient falls asleep, continuous and diffuse slow spikes and waves appear, mainly at $1.5-2.5 \mathrm{~Hz}$, persisting through all the slow-sleep stages. This pattern of continuous spike and wave during slow wave sleep (CSWS) or electrical status epilepticus in slow wave sleep (ESES) tends to be unilateral or clearly lateralized $[43,44]$

Prognosis is variable. Cognitive and behavioural problems occur in more than $3 / 4$ of patients. Complete language recovery is achieved in around $1 / 3$ of patients, while the remaining patients continue to have language deficits of different degrees. The most frequently observed behavioural problems are attention deficit, impulsivity, distractibility, and hyperactivity.

By convention, the LKS is not related to brain organic lesions, and occurs in previously normal children who have already developed age-appropriate speech. However, there are reports of "clinically defined" LKS in patients with congenital or acquired brain lesions, and in children with demonstrated fairly substantial pre-existing anomalies of language development prior to their regression of language.

The most commonly used treatments are clobazam, ethosuximide, sulthiame. Steroids may also be considered. In refractory cases, gamma-globulins, the KD, and surgical treatment should be taken into consideration. Adequate and early treatment management may avoid language and cognitive deterioration.

Bergqvist [45] treated three patients with LKS refractory to traditional treatments who were successfully treated with the KD. All three patients had lasting improvement of their language, behaviour, and seizures for 26,24 , and 12 months, respectively.

\section{EPILEPSY WITH CONTINUOUS SPIKE-WAVES DURING SLOW WAVE SLEEP (CSWS)}

Epilepsy with continuous spike and wave during slow wave sleep (CSWS), also called electrical status epilepticus during slow-wave sleep (ESES), is an epileptic encephalopathy with an age onset between 2 months and 12 years, with a peak at 4 to 5 years. The etiology of CSWS may be genetic or probably genetic, structural, or unknown.

In the evolution of CSWS, three stages are distinguished. In the first stage, before CSWS, the child develops infrequent nocturnal focal motor seizures. In the second stage, with the onset of the CSWS, the frequency of the seizures increases, including typical and atypical absences, myoclonic absences, absence status epilepticus, atonic or clonic seizures, and generalized tonic-clonic seizures. Cognitive deterioration and behavioural disturbances occur. In the third stage, after months or years, the seizures remit and the child improves [3].

The prognosis is variable. The seizures remit in all cases and cognitive and behavioural disturbances improve. However, about half of the cases have severe residual deficits [46]. Seizures are not a major problem as their final prognosis is good. The most appropriate AEDs are valproate, lamotrigine, levetiracetam, and sulthiame. The CSWS may be refractory to classic AEDs, and steroid dependency may occur.

In a study by our group [47], of 65 children with CSWS, 12 (eight boys and four girls) were placed on the KD as add-on to the use of one to three AEDs. Eighteen months after initiating the KD, seven of the initial patients $(58.3 \%)$ remained on the diet. One patient $(8.3 \%)$ became seizure free; one child 
(8.3\%) had a $75 \%-99 \%$ decrease in seizures; two patients (16.6\%) had a $50 \%-74 \%$ decrease in seizures, and the remaining three children (24.9\%) had a less than $50 \%$ seizure reduction. Efficacy of the diet was not found to depend on etiology. We found that the KD is a well-tolerated treatment option for patients with CSWS, not only for structural cases but also for those with an unknown etiology.

Nikanorova [48] evaluated the effect of the KD on electroclinical characteristics and cognitive function in five children (four boys, one girl) aged between 8 and 13 years with CSWS refractory to conventional AEDs, including levetiracetam, and steroids. Electrographic evaluation after 24 months on the KD diet showed CSWS resolution in one patient, mild decrease of the spike-wave index in one, and lack of response in three patients. The KD did not influence the neuropsychological outcome, and intelligence quotient (IQ) scores remained low at the end of the follow-up period. Nevertheless, improvement in attention and behaviour was demonstrated in two patients. These results show that the KD did not appear to influence the neuropsychological outcome. However, the absence of a control group makes it impossible to draw any definite conclusions.

In the series of Ville et al. [14] of 42 consecutive patients where oral steroids were combined with the KD for corticosteroid-resistant or -dependent epileptic encephalopathy, 13 patients had CSWS; eight of them responded well to the diet. In this study, patients presenting with steroid-dependent CSWS seemed to be the best candidates.

\section{FEBRILE INFECTION-RELATED EPILEPSY SYNDROME}

Febrile infection-related epilepsy syndrome (FIRES) is a severe disorder that presents with intractable status epilepticus after a febrile illness in a previously healthy child. Onset is mostly between 3 and 15 years of age, although adults with FIRES have also been described. The syndrome is characterized by three phases: an initial phase with a simple febrile infection; an acute phase, which follows a few days later, with highly recurrent focal seizures that evolve rapidly into refractory status epilepticus, often with no more fever and generally without additional neurological features; and finally a chronic phase consisting of drug-resistant epilepsy and neuropsychological impairment [49].

The etiology of FIRES remains unknown. Immunological, genetic, infectious diseases studies have been unrevealing. Prognosis is poor as most children are left with mild to se- vere cognitive impairment and almost all continue to suffer from severe epilepsy.

In our series [50], three of 12 children with FIRES seen between 1997 and 2012 with a mean time of follow-up of 6.5 years (range, $1-15$ years), two were put on the KD in the acute phase. One patient showed a good and sustained response, with a $50-75 \%$ seizure reduction; the remaining patients had a less than $50 \%$ seizure reduction. Two patients continue on a KD, and they have brief seizures every 2 and 4 months, respectively.

Sing et al. [51] reported two previously healthy schoolaged children who presented with FIRES and were placed on the KD during the acute phase of their illness. Status epilepticus resolved in both. After some months on the KD and other AEDs, they were able to return to school, with some academic accommodations. The authors concluded that the KD may be the treatment of choice in FIRES and that early treatment may control seizures and improve cognitive outcome.

Nabbout et al. [52] studied nine patients with FIRES and refractory status epilepticus seen over 12 years. In seven patients the KD was efficacious. In one responder, early interruption of the diet was followed by relapse of intractable SE, and the patient died. The other six responders developed epilepsy within a few months.

In our last series of 21 patients, five patients were placed on the KD in the acute phase. Two had a $75 \%-99 \%$ seizure reduction; two had a 50\%-74\% reduction; and one did not respond to the diet.

\section{CONCLUSION}

The KD is well tolerated in paediatric patients, including infants, and should be considered early in the therapeutic scheme of EE in refractory cases, regardless of their etiology and age at onset.

Patients that responded well to the diet did not further mentally deteriorate and some even improved behavioural disturbances and cognitive performance.

It is very important to identify the groups of patients with EE in whom the KD works best. Other kinds of diet should also be considered in the treatment of patients with refractory EE.

Future controlled studies would be necessary to better define the efficacy and tolerability of the diet in patients with EE.

\section{Acknowledgments}

None.

\section{Competing interests}

The author has declared that there are no competing interests.
This is an Open Access article distributed under the terms of the Creative Commons Attribution License (http://creativecommons.org/ licenses/by/4.0), which permits unrestricted use, distribution, and reproduction in any medium, provided the original work is properly credited. The Creative Commons Public Domain Dedication waiver (http://creativecommons.org/publicdomain/zero/1.0/) applies to the data made available in this article, unless otherwise stated.

\section{Cite this article as:}

Caraballo: The use of the ketogenic diet in the treatment of epileptic encephalopathies. JICNA 2018 18:66 
Table 1: Summary of clinical characteristics and EEG features at presentation in early and childhood onset epileptic encephalopathy.

\section{Clinical features}

\section{Epilepsy syndrome}

\begin{tabular}{|c|c|c|}
\hline $\begin{array}{l}\text { Age of } \\
\text { seizure } \\
\text { onset }\end{array}$ & Seizure types & $\begin{array}{l}\text { Underlying eti- } \\
\text { ology }\end{array}$ \\
\hline
\end{tabular}

Early infantile

\section{epileptic}

encepha-

lopathy, or

Ohtahara

syndrome

(OS) weeks Tonic seizures

of life

tural abnor-

mality, genetic

abnormalities

(i.e., STXBP1)

Cerebral struc-

$25 \%$ die by 2 years or evolves

to WS and pro-

found disability
EEG features at presentation

Prognosis
$25 \%$ die by 2
years or evolve
to WS and pro-
found disability

\section{Suppression \\ burst pattern in \\ awake and sleep \\ High voltage \\ (150-350uV) \\ paroxysm}

Background

Interictal

Ictal

\begin{tabular}{|c|c|c|}
\hline $\begin{array}{l}\text { Early my- } \\
\text { oclonic en- } \\
\text { cephalopathy } \\
\text { (EME) }\end{array}$ & $\begin{array}{l}\text { First } \\
\text { weeks } \\
\text { of life }\end{array}$ & $\begin{array}{l}\text { Myoclonic } \\
\text { seizures (erratic/ } \\
\text { fragmentary/gen- } \\
\text { eralized); focal } \\
\text { seizures }\end{array}$ \\
\hline
\end{tabular}

Metabolic

genetic etiolo-

gies (nonketotic

hyperglycinemia,

pyridoxine/pyr-

idoxal-5-phos-

phate dependen-

cy, molybdenum

cofactor deficien-

cy, organic acid-

uria, amino-aci-

dopathies)
Generalized paroxysms or focal discharges

\begin{tabular}{|c|c|c|c|}
\hline $\begin{array}{l}50 \% \text { die within } \\
\text { first year or pro- } \\
\text { found disability }\end{array}$ & $\begin{array}{l}\text { Suppression } \\
\text { burst pattern, en- } \\
\text { hanced by sleep }\end{array}$ & $\begin{array}{l}\text { High voltage } \\
\text { (150-350uV) } \\
\text { paroxysm }\end{array}$ & $\begin{array}{l}\text { Generalized par- } \\
\text { oxysms or focal } \\
\text { discharges }\end{array}$ \\
\hline
\end{tabular}

\begin{tabular}{|c|c|c|c|}
\hline $\begin{array}{l}\text { Migrating fo- } \\
\text { cal seizures } \\
\text { in infancy }\end{array}$ & $\begin{array}{l}3 \\
\text { months }\end{array}$ & $\begin{array}{l}\text { Focal motor } \\
\text { seizures with } \\
\text { autonomic mani- } \\
\text { festations }\end{array}$ & $\begin{array}{l}\text { Unknown; } \\
\text { SCN1A, PLCB1, } \\
\text { KCNT1 muta- } \\
\text { tions; } \\
\text { 2q24, 16p11.2 } \\
\text { copy number } \\
\text { variants }\end{array}$ \\
\hline
\end{tabular}

$\begin{array}{ll}\begin{array}{l}\text { West syn- } \\ \text { drome }\end{array} & 3-8 \\ \text { months } & \text { Epileptic spasms }\end{array}$

Heterogenous (congenital cortical malformations, tuberous sclerosis, trisomy 21 , trisomy 18 CDKL5, ARX,

Febrile status epilepticus, alternat-

Dravet syn- 6 drome (DS) months ing hemiconvul- $\quad 80 \%$ SCN1A sions $\rightarrow$ absence, mutation and myoclonic seizures
High mortality

before 1 year

or profound disability (cortical visual impairment; acquired microcephaly)

\section{Hemispheric} background slowing
Multifocal discharges, maximal in temporal and rolandic regions
Rhythmic, monomorphic alpha or theta discharges in noncontiguous brain regions
Depends on etiology; other seizure types evolve by about 5 years
Poorly organized, high amplitude (500-1000 mV), generalized slowing
Multifocal epileptiform discharges with generalized electrodecrement
Generalized sharp wave followed by electrodecrement

$$
\text { SSE }
$$

$\begin{array}{lll} & \\ \text { ESES-related } & 5-8 \\ \text { syndromes } & \text { years } & \text { Focal seizures }\end{array}$
MECP2)

$\begin{array}{ll}\text { MECP2) } & \text { Mortality in child- } \\ 80 \% \text { SCN1A } & \text { hood } 10 \%, \text { intel- } \\ \text { mutation } & \text { lectual disability, } \\ & \text { or crouched gait } \\ & \text { without spasticity } \\ \text { in adults }\end{array}$

$\begin{array}{lll}\text { Normal, gener- } & \begin{array}{l}\text { Generalized, } \\ \text { multifocal or }\end{array} & \begin{array}{l}\text { Generalized par- } \\ \text { alized or focal }\end{array} \\ \text { flowing } & \begin{array}{l}\text { focal discharges; } \\ \text { photoparoxysmal } \\ \text { response }\end{array} & \begin{array}{l}\text { discharges } \\ \text { disch on }\end{array}\end{array}$

Focal/multifocal/ generalized discharges; marked sleep activation with increased interictal spatial

Relapsing-remitCSWS structural; ting course or LKS unknown age limiting by teenage years
Normal or focal/ diffuse slowing

\section{distribution or bi-} lateral synchrony; sleep spike wave index > $85 \%$; CSWS-frontal predominant LKS-temporal predominant 
Len-

nox-Gastaut 1-8 syndrome years (LGS)

Multiple (tonic, atonic, absences, myoclonic, or Heterogeneous focal)

$\begin{array}{lll} & & \\ & & \text { Frequent slow } \\ \text { Intellectual dis- } & \text { Normal or gener- } & \begin{array}{l}\text { spike waves } \\ \text { ability }\end{array} \\ \text { alized slowing } & \begin{array}{l}1.5-2.5 \mathrm{~Hz} \text { or } \\ \text { multifocal }\end{array}\end{array}$

Absence-low spike and waves; tonic-generalized attenuation with recruiting rhythm; atonic-generalized polyspike/ spike waves, or attenuation; myoclonic-generalized polyspike/ spike waves

Generalized polyspike-andwave discharges; or polyspike-andphotoparoxysmal wave response
$50 \%$ normal Normal or mild cognition at last diffuse/focal follow up
Myoc-

lonic-aton
epilepsy

7 6 years months-
Multiple (atonic, sences, or rarely tonic) myoclonic, ab-

No consistent etiology

\section{Inborn errors}

of metabolism and mitochondrial disorders

Progressive myoclonic epilepsies
Varies by etiology
Prominent myocIonic seizures
(Tay-Sachs, Alpers syndrome, Lafora disease, Unverricht-Lundborg disease, or neuronal ceroid lipofuscinosis)
Generalized/multifocal discharges; photoparox-
Developmental regression/dementia; mortality depends on etiology
Generalized slowing ysmal response in Unverricht-Lundborg and neuronal ceroid lipofuscinosis
Generalized discharges

ESES: electrical status epilepticus in slow wave sleep; CSWS: Continuous spike and wave during slow wave sleep; LKS: Landau-Kleffner syndrome; WS: West syndrome 


\section{REFERENCES}

1. Berg AT, Berkovic SF, Brodie MJ, Buchhalter J, Cross $\mathrm{JH}$, van Emde Boas W, Engel J, French J, Glauser TA, Mathern GW, Moshé SL, Nordli D, Plouin P, Scheffer IE. Revised terminology and concepts for organization of seizures and epilepsies: report of the ILAE Commission on Classification and Terminology, 2005-2009. Epilepsia 2010 Apr;51(4):676-85.

2. Vigevano F, Specchio N. Concept of epileptic encephalopathy: is it relevant? In Seizures and syndromes of onset in the two first years of life. Edited by Moshé S, Cross JH, Bellescize de J, Vries de L, Nordli D, Vigevano F. John Libby Eurotext; Montrouge, 2015:155-161.

3. Panayiotopoulos CP. The Epilepsies: Seizures, Syndromes and Management. Bladon Medical Publishing; Oxfordshire, 2005.

4. Howell KB, Harvey AS, Archer JS. Epileptic encephalopathy: Use and misuse of a clinically and conceptually important concept. Epilepsia. 2016 Mar;57(3):343-7.

5. Coppola G, Verrotti A, Ammendola E, Operto FF, Corte RD, Signoriello G, Pascotto A. Ketogenic diet for the treatment of catastrophic epileptic encephalopathies in childhood. Eur J Paediatr Neurol. 2010 May;14(3):22934.

6. Kossoff EH, Zupec-Kania BA, Amark PE, Ballaban-Gil KR, Christina Bergqvist AG, Blackford R, Buchhalter JR, Caraballo RH, Cross JH, Dahlin MG et al. Optimal clinical management of children receiving the ketogenic diet: recommendations of the International Ketogenic Diet Study Group. Epilepsia. 2009 Feb;50(2):304-17.

7. Nangia S, Caraballo RH, Kang HC, Nordli DR, Scheffer IE. Is the ketogenic diet effective in specific epilepsy syndromes? Epilepsy Res. 2012 Jul;100(3):252-7.

8. Beal JC, Cherian K, Moshe SL. Early-Onset Epileptic Encephalopathies: Ohtahara Syndrome and Early Myoclonic Encephalopathy. Pediatr Neurol. 2012 Nov;47(5):317-23.

9. Cusmai R, Martinelli D, Moavero R, Dionisi Vici C, Vigevano F, Castana C, Elia M, Bernabei S, Bevivino E. Ketogenic diet in early myoclonic encephalopathy due to non ketotic hyperglycinemia. Eur J Paediatr Neurol. 2012 Sep;16(5):509-13.

10. Fusco L, Serino D, Barcia G, Nabbout R. Genetic basis of epileptic encephalopathy. In Seizures and syndromes of onset in the two first years of life. Edited by Moshé S, Cross JH, Bellescize de J, Vries de L, Nordli D, Vigevano F. JH John Libby Eurotext; Montrouge, 2015:61-70.

11. Sivaraju A, Nussbaum I, Cardoza CS, Mattson RH. Substantial and sustained seizure reduction with ketogenic diet in a patient with Ohtahara syndrome. Epilepsy Behav 2015 May 15;3:43-5.

12. Ishii M, Shimono M, Senju A, Kusuhara K, Shiota N. [The ketogenic diet as an effective treatment for Ohtahara syndrome]. No To Hattatsu. 2011 Jan;43(1):47-50.

13. Nordli DR, Kuroda MM, Carroll J, Koenigsberger DY, Hirsch LJ, Bruner HJ, Seidel WT, De Vivo DC. Experience with the ketogenic diet in infants. Pediatrics 2001 Jul;108(1):129-33.

14. Ville D, Chiron C, Laschet J, Dulac O. The ketogenic diet can be used successfully in combination with corticosteroids for epileptic encephalopathies. Epilepsy Behav. 2015 Jul;48:61-5.

15. Hirano $Y$, Oguni $H$, Shiota $M$, Nishikawa A, Osawa M. Ketogenic diet therapy can improve ACTH-resistant
West syndrome in Japan. Brain Dev. 2015 Jan;37(1):1822.

16. Lee J, Lee JH, Yu HJ, Lee M. Prognostic factors of infantile spasms: role of treatment options including a ketogenic diet. Brain Dev. 2013 Sep;35(8):821-6.

17. Pires ME, llea A, Bourel E, Bellavoine V, Merdariu D, Berquin P, Auvin S. Ketogenic diet for infantile spasms refractory to first-line treatments: an open prospective study. Epilepsy Res. 2013 Jul;105(1-2):189-94.

18. Numis AL, Yellen MB, Chu-Shore CJ, Pfeifer $\mathrm{HH}$, Thiele EA. The relationship of ketosis and growth to the efficacy of the ketogenic diet in infantile spasms. Epilepsy Res. 2011 Sep;96(1-2):172-5.

19. Kang HC, Lee YJ, Lee JS, Lee EJ, Eom S, You SJ, Kim $\mathrm{HD}$. Comparison of short- versus long-term ketogenic diet for intractable infantile spasms. Epilepsia 2011 Apr;52(4):781-7.

20. Hong AM, Turner Z, Hamdy RF, Kossoff EH. Infantile spasms treated with the ketogenic diet: prospective single-center experience in 104 consecutive infants. Epilepsia 2010 Aug;51(8):1403-7.

21. Kossoff EH, Hedderick EF, Turner Z, Freeman JM. A case-control evaluation of the ketogenic diet versus ACTH for new-onset infantile spasms. Epilepsia 2008 Sep;49(9):1504-9.

22. Caraballo RH, Flesler S, Noli D, Soraru A, Cersósimo R, Bartuluchi M. Symptomatic epileptic spasms in clusters without hypsarrhythmia: surgical management of two cases. Childs Nerv Syst. 2013 Jan;29(1):145-8.

23. Oguni H, Funatsuka M, Sasaki K, Nakajima T, Yoshii K, Nishimura T, Osawa M. Effect of ACTH therapy for epileptic spasms without hypsarrhythmia. Epilepsia 2005 May;46(5):709-15.

24. Caraballo RH, Fortini S, Reyes G, Carpio Ruiz A, Sanchez Fuentes SV, Ramos B. Epileptic spasms in clusters and associated syndromes other than West syndrome: A study of 48 patients. Epilepsy Res. 2016 Mar 24;123:29-35.

25. Caraballo RH, Cersósimo RO, Sakr D, Cresta A, Escobal $\mathrm{N}$, Fejerman N. Ketogenic diet in patients with Dravet syndrome. Epilepsia 2005 Sep;46(9):1539-44.

26. Caraballo RH. Nonpharmacologic treatments of Dravet syndrome: focus on the ketogenic diet. Epilepsia 2011 Apr;52 Suppl 2:79-82.

27. Nabbout R1, Copioli C, Chipaux M, Chemaly N, Desguerre I, Dulac O, Chiron C. Ketogenic diet also benefits Dravet syndrome patients receiving stiripentol: a prospective pilot study. Epilepsia 2011 Jul;52(7):e54-7.

28. Dressler A, Trimmel-Schwahofer P, Reithofer E, Mühlebner A, Gröppel G, Reiter-Fink E, Benninger F, Grassl R, Feucht M. Efficacy and tolerability of the ketogenic diet in Dravet syndrome - Comparison with various standard antiepileptic drug regimen. Epilepsy Res. 2015 Jan;109:81-9.

29. Laux L, Blackford R. The ketogenic diet in Dravet syndrome. J Child Neurol. 2013 Aug;28(8):1041-4

30. Coppola G, Plouin P, Chiron C, Robain O, Dulac O. Migrating partial seizures in infancy: a malignant disorder with developmental arrest. Epilepsia 1995 Oct;36(10):1017-24.

31. Coppola G. The role of ketogenic diet. In Seizures and syndromes of onset in the two first years of life. Edited by Moshé S, Cross JH, Bellescize de J, Vries de L, Nor- 
dli D, Vigevano F. JH John Libby Eurotext; Montrouge, 2015 pp 235-248.

32. Caraballo R, Noli D, Cachia P. Epilepsy of infancy with migrating focal seizures: three patients treated with the ketogenic diet. Epileptic Disord. 2015 Jun;17(2):194-7.

33. Oguni H. Treatment and long-term prognosis of myoclonic-astatic epilepsy of early childhood. Neuropediatrics 2002;33:122-32.

34. Caraballo RH, Cersósimo RO, Sakr D, Cresta A, Escobal N, Fejerman N. Ketogenic Diet in Patients with Myoclonic-Astatic Epilepsy. Epileptic Disord. 2006 Jun;8(2):151-5

35. Sills MA, Forsythe WI, Haidukewych D, MacDonald A, Robinson $\mathrm{M}$. The medium chain triglyceride diet and intractable epilepsy. Arch Dis Child 1986;61:1168-1172.

36. Laux L, Devonshire K, Goldstein J, Nordli D. Efficacy of the ketogenic diet in myoclonic epilepsy of Doose. Epilepsia 2004;45(suppl 7):251..

37. Caraballo RH, Cersósimo RO, Espeche A, Arroyo HA Fejerman N. Myoclonic status in nonprogressive encephalopathies: study of 29 cases. Epilepsia 2007 Jan;48(1):107-13.

38. Cross $\mathrm{JH}$. The ketogenic diet in the treatment of Lennox-Gastaut syndrome. Dev Med Child Neurol. 2012 May;54(5):394-5.

39. Cersósimo RO, Bartuluchi M, Fortini S, Soraru A, Pomata $\mathrm{H}$, Caraballo $\mathrm{RH}$. Vagus nerve stimulation: effectiveness and tolerability in 64 paediatric patients with refractory epilepsies. Epileptic Disord. 2011 Dec;13(4):382-8.

40. Caraballo RH, Fortini S, Flesler S, Armeno M, Ariela A, Cresta A, Mestre G, Escobal N. Ketogenic diet in patients with Lennox-Gastaut syndrome. Seizure 2014 Oct;23(9):751-5.

41. Lemmon ME, Terao NN, Ng YT, Reisig W, Rubenstein JE, Kossoff EH. Efficacy of the ketogenic diet in Lennox-Gastaut syndrome: a retrospective review of one institution's experience and summary of the literature. Dev Med Child Neurol. 2012 May;54(5):464-8.

42. Sharma S, Jain P, Gulati S, Sankhyan N, Agarwala A. Use of the modified Atkins diet in Lennox Gastaut syndrome. J Child Neurol. 2015 Apr;30(5):576-9.
43. Pearl PL, Carrazana EJ, Holmes GL. The Landau-Kleffner Syndrome. Epilepsy Curr. 2001 Nov;1(2):39-45.

44. Caraballo $\mathrm{RH}$, Cejas N, Chamorro N, Kaltenmeier MC, Fortini S, Soprano AM. Landau-Kleffner syndrome: a study of 29 patients. Seizure 2014 Feb;23(2):98-104.

45. Bergqvist AG, Chee CM, Lutchka LM, Brooks-Kayal AR. Treatment of acquired epileptic aphasia with the ketogenic diet. J Child Neurol. 1999; 14:696-701.

46. Loddenkemper T, Fernández IS, Peters JM. Continuous spike and waves during sleep and electrical status epilepticus in sleep. J Clin Neurophysiol. 2011 Apr;28(2):154-64.

47. Reyes G, Flesler S, Armeno M, Fortini S, Ariela A, Cresta A, Mestre G, Caraballo RH. Ketogenic diet in patients with epileptic encephalopathy with electrical status epilepticus during slow sleep. Epilepsy Res. 2015 Jul;113:126-31.

48. Nikanorova M, Miranda MJ, Atkins M, Sahlholdt L. Ketogenic diet in the treatment of refractory continuous spikes and waves during slow sleep. Epilepsia 2009 May;50(5):1127-31.

49. van Baalen $A 1$, Häusler $M$, Boor R, Rohr A, Sperner J, Kurlemann G, Panzer A, Stephani U, Kluger G. Febrile infection-related epilepsy syndrome (FIRES): a nonencephalitic encephalopathy in childhood. Epilepsia 2010;51(7):1323-8.

50. Caraballo RH, Reyes G, Avaria MF, Buompadre MC, Gonzalez M, Fortini S, Cersosimo R. Febrile infection-related epilepsy syndrome: a study of 12 patients. Seizure 2013 Sep;22(7):553-9.

51. Singh RK, Joshi SM, Potter DM, Leber SM, Carlson $M D$, Shellhaas RA. Cognitive outcomes in febrile infection-related epilepsy syndrome treated with the ketogenic diet. Pediatrics 2014 Nov;134(5):e1431-5.

52. Nabbout R, Mazzuca M, Hubert P, Peudennier S, Allaire C, Flurin V, Aberastury M, Silva W, Dulac O. Efficacy of ketogenic diet in severe refractory status epilepticus initiating fever induced refractory epileptic encephalopathy in school age children (FIRES). Epilepsia 2010 Oct;51(10):2033-7. 